\title{
National audit of epistaxis management
}

It is sometimes tempting to malign the current tranche of junior doctors; punishing shift patterns lead to frequent absences from operating theatres, and, when present, some seem so demoralised one wonders if they will last the distance. It is a tough time to be a trainee in any specialty, but it seems the impact of contract changes has been felt most acutely in the surgical specialties. At a time, therefore, when most should be running for the hills, our ENT trainees instead have come together to deliver a carefully planned, well executed and meticulously presented National Audit of Epistaxis Management.

The ENT-UK Audit Group had toyed with the idea of an epistaxis audit for some time, having developed a local audit into a small pilot. However, a lack of funding, and, being honest, a lack of enthusiasm from the consultant members, who are often removed from the daily management of patients with epistaxis, meant the project faltered. Then along came Integrate, the National ENT Trainee Research Collaborative, ${ }^{1}$ and my greatest contribution to the project was to realise they would do a much better job. Although Sean Carrie and I have subsequently sat on the Executive Steering Group, our input has been supportive, but limited. Junior doctors are very much on the frontline with the management of epistaxis, and, with a promise of fair recognition for their contribution, are ideally placed to capture the data. What is perhaps surprising is how well they have managed the process and then critically evaluated the results.

Dissatisfied with the lack of clear 'gold standards' against which to audit care, the team first decided they would develop the standards de novo, based on a suite of comprehensive literature reviews published alongside the main audit. In order to assimilate the often poor-quality evidence and produce guidelines, a consensus meeting was convened, where all the evidence was considered and debated. Then followed a Delphi-type process, where the consensus panel were asked to express levels of agreement with the recommendations until consensus was reached. The guidelines presented are the result of an enormous amount of work by dozens of junior doctors.

After piloting a data collection tool, ${ }^{2}$ the full National Audit of Epistaxis Management was launched late last year. The group managed to achieve ascertainment levels of 94 per cent of epistaxis admissions across 113 National Health Service (NHS) hospitals across the UK, on a shoestring budget provided by ENT-UK. In contrast, the National Audit of Surgery for Chronic Rhinosinusitis, with the support of the Royal College of Surgeons of England, and considerable financial input, captured 77 per cent of eligible cases in 87 NHS hospitals.

So, what of the findings? Will this revolutionise the care of epistaxis patients? Probably not - what they find is that actually, by and large, we are pretty good at managing patients with epistaxis. I was particularly pleased that there is no evidence that consultant input is beneficial for the majority of these patients, so I can sleep soundly at night when on call. There are things we can do better - early consideration of cautery may reduce length of stay, for example; don't always just reach for the nasal packs. We should also perhaps be a little concerned; over 51 per cent of patients were on anticoagulation, so this is not a problem that is likely to fall in prevalence anytime soon. ${ }^{3,4}$

What this does show, more than anything, is that the future lies in the hands of our junior doctors, but we have no reason to be fearful. We have a hardworking, intelligent, inspirational group of junior doctors; many will have had their first taste of collaborative research, but several, I am sure, will go on to become our academic leaders in the future. Before the ink has dried on the last paper, there are already mutterings of their next project; perhaps a trial, or two, or more... As our Editors at The Journal of Laryngology \& Otology have commented previously, the future of ENT is in very safe hands. ${ }^{5}$

Congratulations to all involved in the National Audit of Epistaxis Management - you have done a fantastic job and should be extremely proud of your achievements. To the Steering Group, you have all been outstanding, and I could not have put the project in better hands. Thank you also to The Journal for permitting the articles to be published together.

Finally, The Journal Senior Editors would like to take this opportunity to thank all those who have contributed to the success of this year's journal, including all the authors, Assistant Editors, reviewers, advisers, production staff, our publishing partners 
at Cambridge University Press and all other colleagues at The Journal, for their dedication, enthusiasm and hard work. Finally, we wish all of our readers a happy and successful 2018 .

CLAIRE HOPKINS, Invited Editor

JONATHAN FISHMAN, ROBIN YOUNGS, EDWARD FISHER, MUSHEER HUSSAIN, Senior Editors
References

1 ENT Trainee Research Collaborative - West Midlands. National prospective cohort study of peritonsillar abscess management and outcomes: the Multicentre Audit of Quinsies study. J Laryngol Otol 2016;130:768-76

2 Mehta N, Williams RJ, Smith ME, Hall A, Hardman JC, Cheung L et al. Can trainees design and deliver a national audit of epistaxis management? A pilot of a secure web-based audit tool and research trainee collaboratives. J Laryngol Otol 2017;131:518-22

3 Kumar S, Moorthy R. New oral anticoagulants - a guide for ENT surgeons. J Laryngol Otol 2016;130:324-8

4 Bola S, Marsh R, Braggins S, Potter C, Hickey S. Does the continuation of warfarin change management outcomes in epistaxis patients? J Laryngol Otol 2016;130:256-60

5 Hussain M, Fisher E, Youngs R, Fishman J. The future of British otorhinolaryngology is in safe hands. J Laryngol Otol 2017;131: 471 